\title{
Kinetic Parameters of the Thermal Oxidation and Degradation Reactions in Soybean Oil and Palm Olein
}

\author{
Alex S. Torquato, ${ }^{a, b}$ Paulo R. S. Bittencourt, ${ }^{\circledR} * b$ Fernando R. Scremin, ${ }^{b}$ \\ Rosana A. da Silva-Buzanello, ${ }^{b}$ Thays R. Gonçalves ${ }^{a}$ and Makoto Matsushita ${ }^{a}$ \\ ${ }^{a}$ Departamento de Química, Universidade Estadual de Maringá (UEM), 87020-900 Maringá-PR, Brazil \\ ${ }^{b}$ Laboratório de Análise Térmica e Espectrometria de Combustíveis e Materiais (LATECOM), \\ Departamento de Química, Universidade Tecnológica Federal do Paraná (UTFPR), \\ Av. Brasil 4232, 85884-000 Medianeira- PR, Brazil
}

\begin{abstract}
Partially hydrogenated soybean oil and palm olein are oils that are widely used in the food industry. Continuous contact with air may cause changes of the triglycerides chemical structure, to eventually produce substances of lower molar masses that may be toxic to mammals. This study aimed to determine the kinetic parameters for the thermal oxidation of these oils and of their residual used oils from the pre-frying industrial step on preparing breaded chicken meat. The main reactions were followed by thermogravimetry (TG) and differential scanning calorimetry (DSC); the formation of the produced substances was monitored by gas chromatography flame ionization detector (GC-FID) and Fourier transform infrared spectroscopy (FTIR). These analyses indicated different chemical pathways, according to the type of unsaturation and changes in the molecular structures of the fatty acids in the oils. From the thermal analysis, more than one decomposition event was observed during the thermal oxidation process. As the soybean oil has a lower oxidation onset temperature than palm olein, it has lower rate of mass loss, with a higher activation energy value.
\end{abstract} FID

Keywords: oil quality, thermo-oxidative stability, thermal analysis, FTIR, gas chromatography-

\section{Introduction}

Modern lifestyles create a high demand for products that are convenient, fast, and easy to prepare, such as industrially processed meat, which are usually prepared through the method of frying by immersion. This is one of the food preparation procedures most used by food industries, snack bars, and restaurants and also in domestic kitchens. The process involves food dehydration and uses vegetal oils or animal fats as a heat transfer medium. ${ }^{1}$ Fried foods have aroma, taste, and texture properties that cannot be provided by any other usual cooking methods. The industrial production of fried breaded chicken includes a pre-frying stage, to coagulate the batter around the substrate so that it gets the proper consistency for subsequent freezing. The pre-frying stage also aims to contribute to a better color and appearance. The adsorbed oil acts to protect the product from dehydration on freezing. ${ }^{2}$ The range of

*e-mail: paulob@utfpr.edu.br temperatures in the pre-frying stage is set to be between 150 and $190^{\circ} \mathrm{C}$. The direct contact with air (open system) causes some chemical changes in the oils or fat, including hydrolysis, oxidation, polymerization, pyrolysis. ${ }^{3-6}$ These reactions modify the physical and chemical properties of the oils fatty medium due to the saturation reaction and also by releasing compounds of lower molar mass than the original triacylglyceride, such as carbonyl and carboxylic compounds. ${ }^{7-9}$

Oil oxidation does not occur in a single step; the process instead starts by the formation of primary oxidation products such as peroxides and free fatty acids. After this, secondary substances such as carbonyls, aldehydes, dienes, and trienes are formed. The last stage occurs with the formation of oxidized products at different rates and produces substances with low molecular mass, as triacylglycerides, which are released to the atmosphere. The reaction conversion rate and the nature of formed products depend on several factors such as the oil's source, the temperature, the availability of oxygen and light, and the presence of moisture and metals. 
These chemical modifications of the oils are also known as rancidification. ${ }^{8,10,11}$ Thermogravimetric analysis (TG) and differential scanning calorimetry (DSC) are techniques commonly used to determine thermal stability and the oxidation inductive time (OIT) of oils, as well as the determination of some kinetic parameters. ${ }^{12-15}$

The present study aimed to evaluate the thermal oxidative stability, degradation rate, and kinetic parameters for soybean oil and palm olein samples as followed by thermogravimetry (TG). Samples of commercial oils used to prepare breaded chickens, before and after the pre-fried process, were obtained from a food industry located in the western region of the Paraná state, in Brazil. Samples were characterized by gas chromatography flame ionization detector (GC-FID), Fourier transform infrared spectroscopy (FTIR), TG and DSC.

\section{Experimental}

\section{Materials and methods}

Samples of partially hydrogenated soybean oil (COAMO, Campo Mourão, Paraná, Brazil) and palm olein (Agropalma, Limeira, São Paulo, Brazil) were industrially fractionated from refined palm oil, free of antioxidant additives, in an industrial plant for foods located in Matelândia, Paraná state, Brazil. In addition to the commercial samples of soybean oil (sample s90) and palm olein (sample a80), other samples from residual oils from the breaded chicken pre-frying process were separated after being used for 2 and 4 days: samples labeled as s 92 and s94, respectively, for the soybean oil, and a82 and a84, for the residual palm olein samples, obtained from an automated and continuous pre-frying industrial process, running in an open environment.

\section{Dynamic thermogravimetric analysis}

TG were carried in a simultaneous thermal analyzer (STA 6000 PerkinElmer ${ }^{\mathrm{TM}}$, USA). For each sample, $12 \mathrm{mg}$ of lipid matrix was placed into an open platinum crucible and heated from 50 to $600{ }^{\circ} \mathrm{C}$ at a heating rate of $10^{\circ} \mathrm{C} \mathrm{min}^{-1}$ under inert $\left(\mathrm{N}_{2}\right)$ and oxidizing $\left(\mathrm{O}_{2}\right)$ dynamic atmospheres, flow rate of $50 \mathrm{~cm}^{3} \mathrm{~min}^{-1}$. Both gases (White Martins ${ }^{\mathrm{TM}}$, Brazil) were $99.999 \%$ grade.

\section{Analyses of the oil oxidative stability by DSC}

The samples of these commercial oils were put into open platinum crucibles in a simultaneous thermal analyzer (STA6000 PerkinElmer, USA) and were analyzed at four different isotherms: $120,130,140$, and $150{ }^{\circ} \mathrm{C}$. The temperature was increased up to the isothermal in an inert atmosphere $\left(\mathrm{N}_{2}\right.$; White Martins ${ }^{\mathrm{TM}}$, Brazil $99.999 \%$ grade) with a flow rate of $50 \mathrm{~cm}^{3} \mathrm{~min}^{-1}$. After reaching the set temperature, the atmosphere became oxidizing $\left(\mathrm{O}_{2}\right.$; White Martins ${ }^{\mathrm{TM}}$, Brazil $99.999 \%$ grade) with a flow rate of $50 \mathrm{~cm}^{3} \mathrm{~min}^{-1}$. These analyses were carried out until the sample reached the oxidation (onset temperature, $\mathrm{T}_{\text {onset }}$ ).

The parameters of the oils by TG

Similar procedures were carried for the sample analysis as for the oxidative stability of the oils by DSC; however, the temperature settings were $170,180,190$, and $200^{\circ} \mathrm{C}$. The scanning time was set to $40 \mathrm{~min}$.

Samples of the commercial oils were heated to $190{ }^{\circ} \mathrm{C}$ for $400 \mathrm{~min}$ in order to assess the degradation profile and to determine the kinetic parameters of the thermal degradation stage followed by mass loss (post oxidation stage). This was done in such a way to simulate the industrial parameters. The residual mass of the samples was analyzed by GC-FID and FTIR.

Fourier-transform infrared spectroscopy-attenuated total reflection mode

The infrared spectra of the samples were obtained by an FTIR spectrometer PerkinElmer ${ }^{\mathrm{TM}}$ Frontier (USA), using the attenuated total reflectance mode (ATR) in the wavenumber range of $4000-600 \mathrm{~cm}^{-1}$, resolution of 4 points per $\mathrm{cm}^{-1}$ and 4 spectra accumulations per second.

\section{Fatty acid methyl ester composition}

The fatty acid methyl esters (FAME) were prepared by methylation of the total lipid (TL), and the analyses were performed in triplicate. Esters were separated by a GC-FID (PerkinElmer ${ }^{\mathrm{TM}}$ Clarus 680, USA) equipped with a flame ionization detector and a cyanopropyl capillary column $(100 \mathrm{~m} \times 0.25 \mathrm{~mm}$ internal diameter, $0.25 \mu \mathrm{m}$ film thickness, CP-7420 Varian ${ }^{\mathrm{TM}}$, USA). The chromatographic column used for the oil samples was set to $80^{\circ} \mathrm{C}$, remaining for $1 \mathrm{~min}$ to $180^{\circ} \mathrm{C}\left(15^{\circ} \mathrm{C} \mathrm{min}-1\right)$. At this temperature range, it is possible to identify the esters from $\mathrm{C} 6$ to saturated $\mathrm{C} 18$. After that, the system was set to $220^{\circ} \mathrm{C}\left(3{ }^{\circ} \mathrm{C} \mathrm{min}-1\right)$, remaining at this temperature for $2 \mathrm{~min}$ in order to identify ester of $\mathrm{C} 18$ unsaturated fatty acid. It was set a heating rate of $5{ }^{\circ} \mathrm{C} \mathrm{min}{ }^{-1}$ until reaching $250{ }^{\circ} \mathrm{C}$, the system was kept at this temperature for $5 \mathrm{~min}$, so to allow identify FAMEs higher than $\mathrm{C} 18$. Helium was mixed to the carrier gas at a flow rate of $1.0 \mathrm{~cm}^{3} \mathrm{~min}^{-1}$; hydrogen and synthetic air 
were the flame gases at 40 and $400 \mathrm{~cm}^{3} \mathrm{~min}^{-1}$ flow rate, respectively. ${ }^{16,17}$ The peak areas of the chromatograms were determined by the TotalChrom ${ }^{\circledR}$ software, and the retention times values were compared with the methyl ester standards (Supelco ${ }^{\mathrm{TM}}$, USA).

\section{Results and Discussion}

The fatty acid (FA) and the methyl ester compositions in the commercial soybean oil (s90) and palm olein (a80), as determined by GC-FID are shown in Figure 1. It is possible to note the differences in the FA profile of the samples; the content of the trans fatty acids is higher in the soybean oil. For the cis fatty acid, the composition is approximately $55 \%$ for both samples. As expected, the presence of saturated molecules is higher in the palm oil. They made up about $40 \%$ of its composition, which is twice the amount presented by the soybean oil.

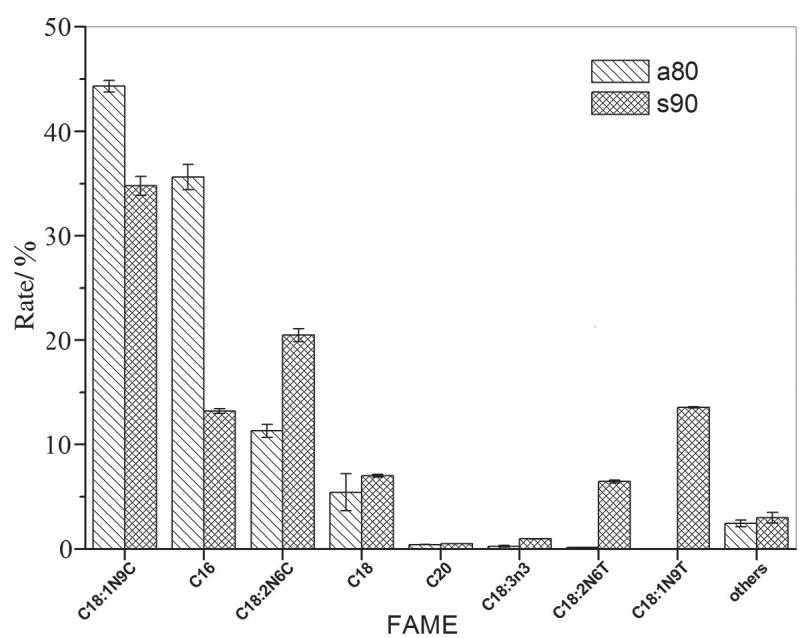

Figure 1. Composition in fatty acid methyl esters (FAME) for the commercial soybean oil and palm olein as received (results from GCFID analyses).

In addition to the FA profile, the differences between the compositions of these oils were also observed by their thermal stability, as depicted in Figure 2. The first derivative of the TG curves (DTG) highlights these differences. ${ }^{18,19}$ From these DTG data, it is observed the beginning of the thermal degradation $\left(\mathrm{T}_{\text {onset }}\right)$ : the sample a 80 is thermally more stable than the s90, which started to degrade at $383{ }^{\circ} \mathrm{C}$, whereas the $\mathrm{T}_{\text {onset }}$ for this palm olein was $392{ }^{\circ} \mathrm{C}$.

The peak of the DTG curve shown in Figure 2 represents the temperature corresponding to the highest mass loss rate for the samples $\left(\mathrm{T}_{\max }\right)$; values were comparable for both soybean oil and palm olein: 433 and $436{ }^{\circ} \mathrm{C}$, respectively. The pyrolysis process led to no residual mass.

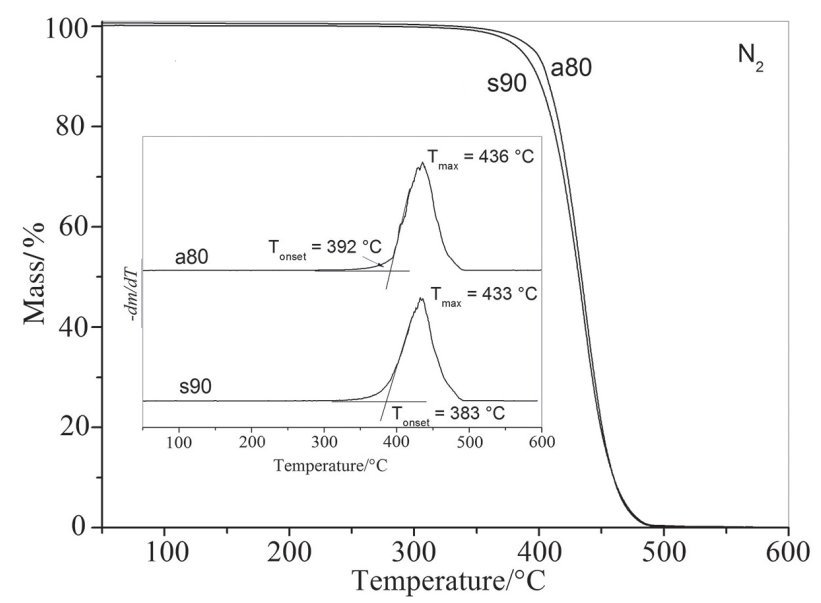

Figure 2. Thermogravimetric curve (TG curve) and first derivative of the TG curve (DTG) for the commercial oil samples under an inert atmosphere.

From the DTG curves for the commercial samples run under oxidizing atmosphere (Figure 3), it is possible to observe significant difference in thermal behavior between the two oil samples. The difference between $\mathrm{T}_{\text {onset }}$ for the two sample was $20^{\circ} \mathrm{C}$. The a 80 sample is thermally more stable, presenting $\mathrm{T}_{\text {onset }}$ at $340{ }^{\circ} \mathrm{C}$ whereas the $\mathrm{T}_{\text {onset }}$ for the s90 oil was $320^{\circ} \mathrm{C}$.

The palm olein also demonstrated more high thermal stability than the soybean oil under oxidizing atmosphere, (Figure 3): $\mathrm{T}_{\text {max }}=355^{\circ} \mathrm{C}$ and $\mathrm{T}_{\max }=337^{\circ} \mathrm{C}$, respectively. However, in the TG and DTG curves, both oils showed mass loss in three thermal events. It was more pronounced (TG curve) for the soybean oil, with $\mathrm{T}^{\prime \prime}{ }_{\text {max }}=430^{\circ} \mathrm{C}$ and $\mathrm{T},{ }^{\prime}{ }_{\max }=540^{\circ} \mathrm{C}$ (Figure 3).

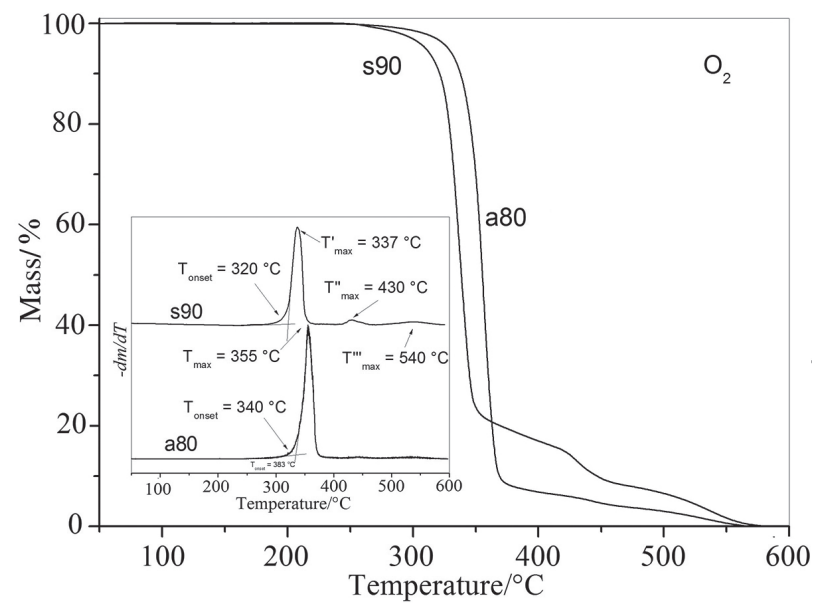

Figure 3. Thermogravimetric curve (TG curve) and first derivative of the TG curve (DTG) of the commercial oil samples (s90 and a80) under an oxidizing atmosphere.

Under an oxidizing atmosphere, the thermal decomposition of the samples of soybean oil and palm 
olein occurs by the following steps: the first mass loss is interpreted as being due to the decomposition of polyunsaturated fatty acids; in a second step, cleavage of the double bonds occurs producing saturated triacylglyceride molecules due to the monounsaturated fatty acids decomposition. The last mass loss event can be related to the thermal decomposition of the remaining saturated fatty acids. ${ }^{16}$ Despite of the fact that the palm olein sample contains a high content of saturated fatty acids, the second and third thermal steps did not appear very intense in the TG curve. That fact can be related to the first and second decomposition steps being quite exothermic, releasing heat in a relatively short time, which was intense enough to cause the oil combustion.

Regarding the mass loss at temperatures below $300^{\circ} \mathrm{C}$, these commercial oil samples remained quite stable. Thus, the physicochemical changes occurring below this temperature can be attributed mainly to events related to the sample nature itself and to the atmosphere used for the analyses.

The measurement of oxidative stability is very important on evaluating and monitoring the oil quality parameters. The oxidation reaction can be influenced by the fatty acids of triacyglyceride structure. The DSC curves for the soybean oil and palm olein are shown in Figures $4 a$ and $4 b$.

From the DSC curves, it is observed the oxidation of the palm olein sample, comparatively to the soybean oil at $120^{\circ} \mathrm{C}$. The induction time value for each isothermal were relatively higher for the palm olein at 130 and $140^{\circ} \mathrm{C}$. This may be related to the high content of saturated fatty acids (Figure 1). The soybean oil presents a higher composition of unsaturated fatty acids with trans configuration which are more effective oxidizing agents at those temperatures. ${ }^{20}$ Therefore, it shows a lower induction time and, as consequence, favors peroxidation reactions and hydrolysis.
These results are consistent with the TG data. The soybean oil tends to be thermally more unstable compared to the palm olein at higher temperatures under an oxidizing atmosphere: at $150{ }^{\circ} \mathrm{C}$ the induction time values were similar.

The assessed values of oxidation induction time $\left(\mathrm{t}_{0}\right)^{21}$ for each isotherm are presented in Table 1.

Table 1. Induction time $\left(\mathrm{t}_{0}\right)$ obtained by differential scanning calorimetry (DSC) of s90 and a 80

\begin{tabular}{lcccc}
\hline \multirow{2}{*}{ Sample } & \multicolumn{4}{c}{$\mathrm{DSC} \mathrm{t}_{0} / \mathrm{min}$} \\
\cline { 2 - 5 } & $120{ }^{\circ} \mathrm{C}$ & $130{ }^{\circ} \mathrm{C}$ & $140{ }^{\circ} \mathrm{C}$ & $150{ }^{\circ} \mathrm{C}$ \\
\hline s90 & 310.7 & 118.9 & 76.3 & 41.6 \\
a80 & 262.8 & 252.3 & 94.4 & 40.1 \\
\hline
\end{tabular}

In this study, a simultaneous thermal analyzer (STA) was used for the oil oxidative stability determination. Hence, it was possible to observe the mass variation of the samples during the oxidation process (Figures $5 \mathrm{a}$ and $5 \mathrm{~b}$ ). The mass increased as a result of the peroxidation process of the unsaturated fatty acid. This was followed by a mass loss caused by the cleavage of double bonds. ${ }^{22,23}$

Other reactions following the thermal oxidation, such as hydrolysis and polymerization, may occur producing esters, short-chain alkanes, dimers and trimers of fatty acids, cyclic compounds, and toxic substances such as $\alpha, \beta$-unsaturated aldehydes. ${ }^{24-26}$ In the industrial pre-frying process, the breading remains in contact with the oil for a short-time. In this industrial procedure, this time was approximately $40 \mathrm{~s}$ at $190{ }^{\circ} \mathrm{C}$. The breaded chicken absorbs a small amount of oil and simultaneously releases water, carbohydrates, and other substances to the oil mass. These substances can accelerate the oxidation process, reducing the oil's quality. Therefore, the industry must replace the oil in a given
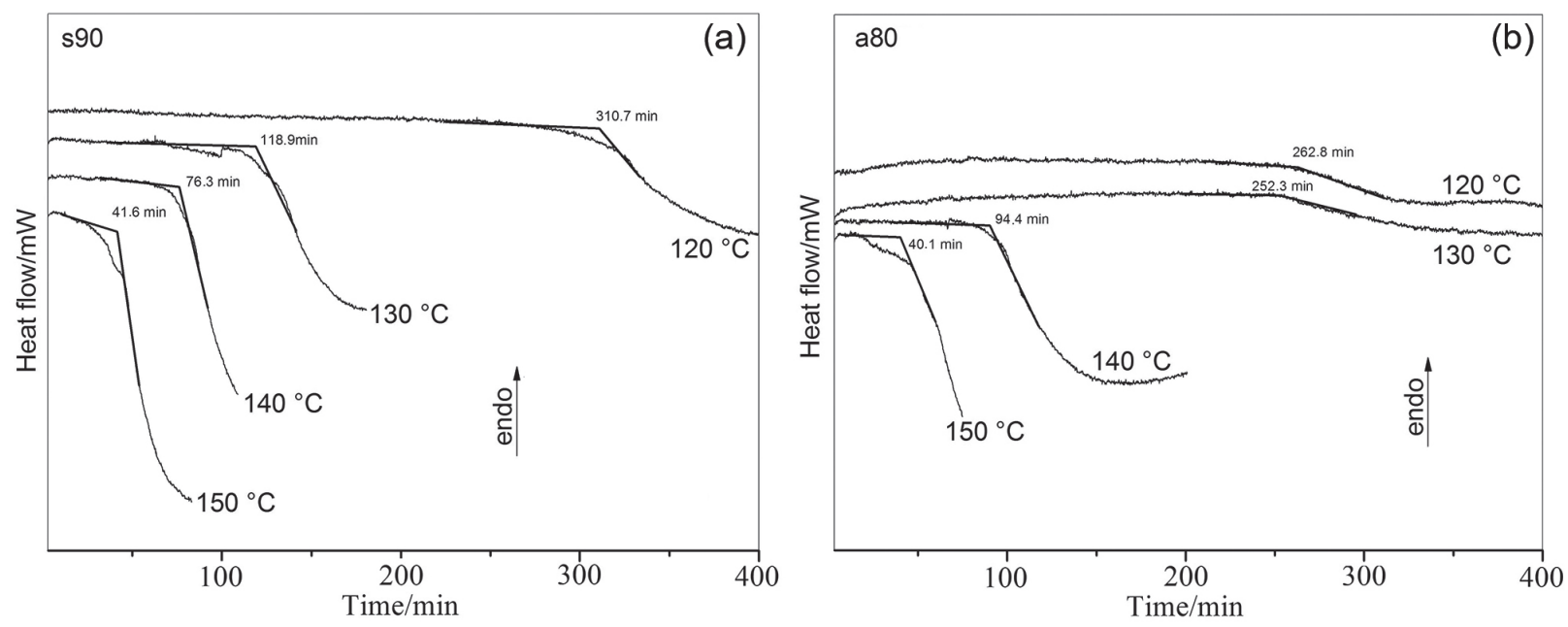

Figure 4. Isothermal differential scanning calorimetric oxidation curves for the commercial (a) partially hydrogenated soybean oil and (b) palm olein. 

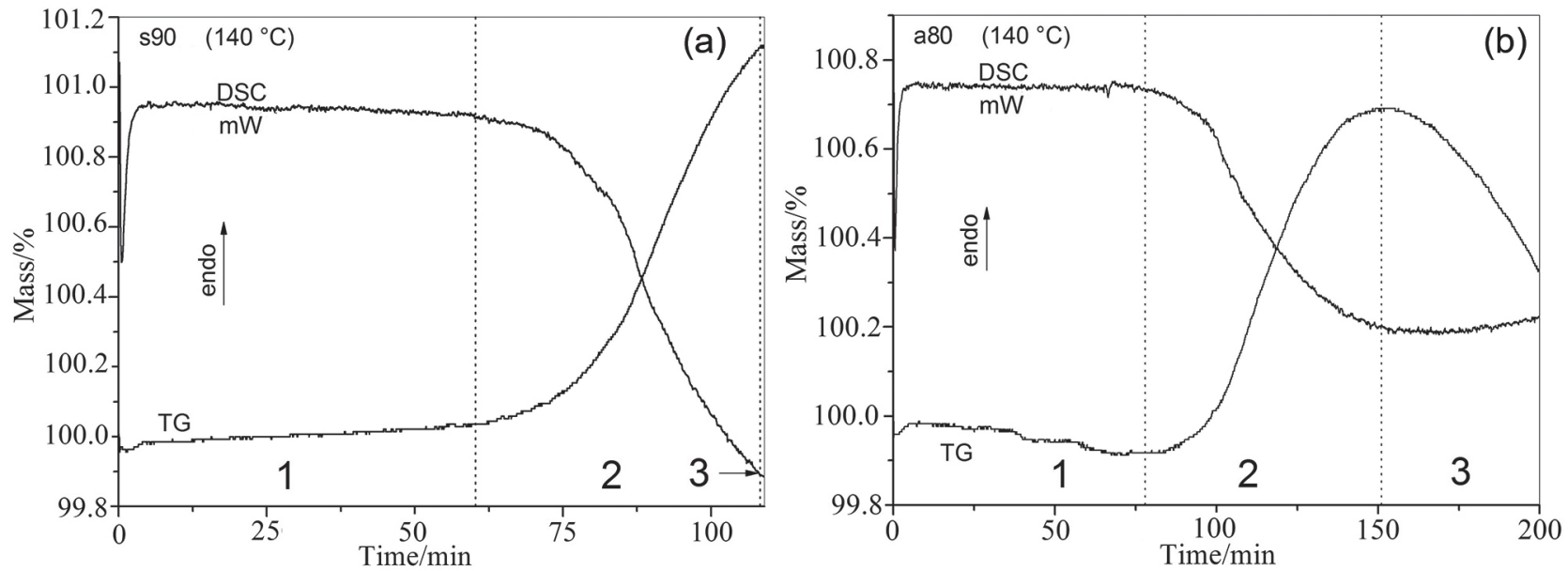

Figure 5. TG and DSC curves from oxidative stability analyses of commercial (a) partially hidrogenated soybean oil and (b) palm olein.

frequency. ${ }^{7,27}$ The FTIR-ATR spectra (Figures 6a and 6b) of the palm olein and soybean oil samples showed differences among unused, industrially used and commercial oils exposed to an oxidizing atmosphere at $190{ }^{\circ} \mathrm{C}$ for $400 \mathrm{~min}$.

The FTIR spectrum for the partially hydrogenated soybean oil sample s90/400 min shows signals in the range of $3600-3100 \mathrm{~cm}^{-1}$. This band also appears in the a84 and a80/400 min samples. This band comes from $\mathrm{O}-\mathrm{H}$ stretching due to the oil oxidation, which causes the formation of the hydroxyl groups. At wavenumbers below $3100 \mathrm{~cm}^{-1}$, the samples presented the same signals, except for those exposed to the $\mathrm{O}_{2}$ atmosphere at $190{ }^{\circ} \mathrm{C}$, for $400 \mathrm{~min}$, whose signal at $3000 \mathrm{~cm}^{-1}\left(\mathrm{sp}^{2} \mathrm{C}-\mathrm{H}\right.$ stretching) disappeared during the saturation process. Band broadening and an increase in signal intensity at $1744 \mathrm{~cm}^{-1}$ (ester $\mathrm{C}=\mathrm{O}$ stretching) was observed. This broadening at the lower wavenumber was attributed to the carbonyl of ketone/aldehyde/carboxyl groups. The band at

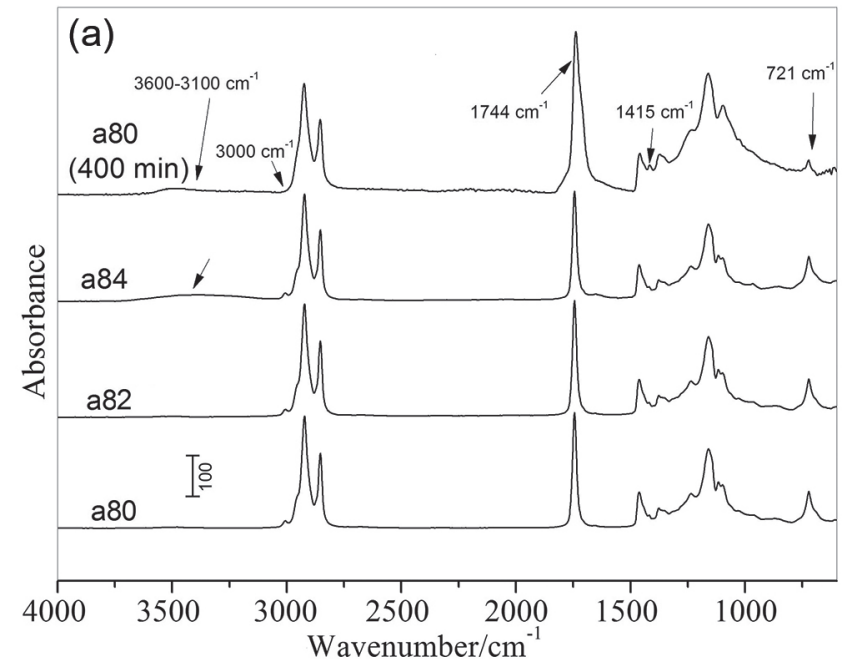

$1416 \mathrm{~cm}^{-1}$ (signal related as $\mathrm{CH}_{3}$ asymmetrical wagging) increased, and a decrease in the band intensity at $721 \mathrm{~cm}^{-1}$ (C-C chain vibration) occured. ${ }^{28}$ These two last signals indicate short-chain alkane formation. In the partially hydrogenated soybean oil (a80/400 min) spectrum, it is possible to observe the absence of the band at $967 \mathrm{~cm}^{-1}$ (hydrogen from $\mathrm{C}=\mathrm{C}$ vibration in trans fatty acid) because of triacylglyceride saturation. ${ }^{29}$

The FAME chromatographic profile from GC-FID (Figures $7 \mathrm{a}$ and $7 \mathrm{~b}$ ) is consistent with the FTIR spectra. The graphs show the variation of the amount of saturated and unsaturated compounds in the oils samples for a certain period of time. However, this variation becomes quite accentuated for the oils that are subjected to prolonged conditions under oxidizing atmosphere, because there is an increase in the formation of $\mathrm{C} 16$ and $\mathrm{C} 8$.

Regarding the partially hydrogenated soybean oil sample (s90/400 min), it is possible to observe an increase

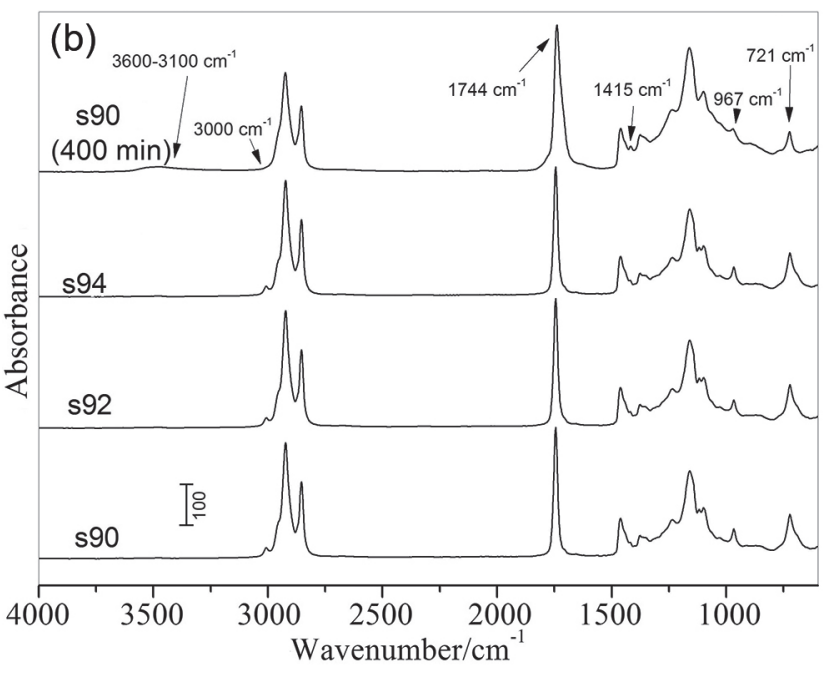

Figure 6. FTIR spectra of unused, used, and commercial samples $\left(\mathrm{O}_{2}\right.$ atmosphere and $190{ }^{\circ} \mathrm{C}$, for $\left.400 \mathrm{~min}\right)$ from (a) partially hydrogenated soybean oil and (b) palm olein. 

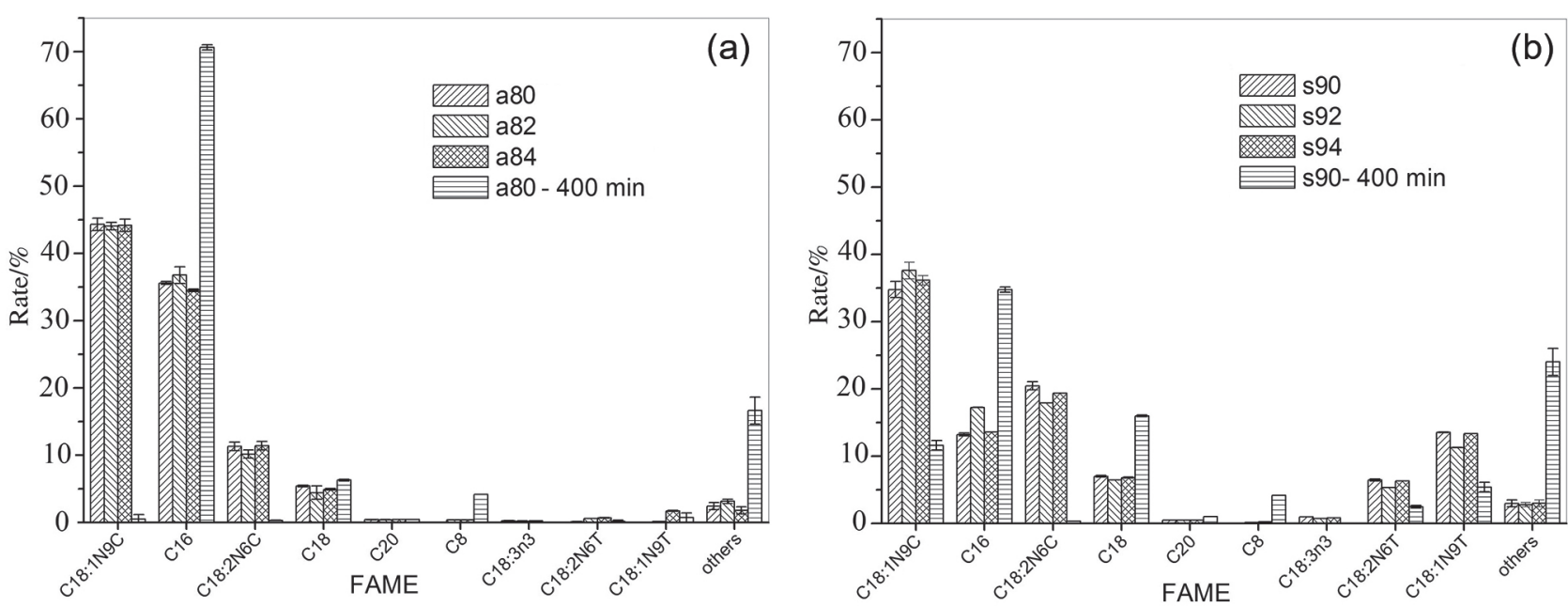

Figure 7. FAME profile of unused, used, and commercial samples $\left(\mathrm{O}_{2}\right.$ atmosphere, $190{ }^{\circ} \mathrm{C}$ for $\left.400 \mathrm{~min}\right)$ for the (a) palm olein and (b) partially hydrogenated soybean oil (results from GC-FID analyses).

of the $\mathrm{C} 18$ content. The same increase is not observed for the palm olein. This demonstrates that the content of the fatty acids C18:2N6C, C18:3n3, C18:2N6T and C18:1N9T in the soybean oil decreases substantially during the saturation process. Consequently, the degradation with mass loss occurs more mildly in the soybean oil sample compared to the palm olein.

The oxidation process followed by degradation of the oils at $190{ }^{\circ} \mathrm{C}$ for 400 min was followed by TG and DSC analyses. Figures $8 \mathrm{a}$ and $8 \mathrm{~b}$ show, respectively, the palm olein and the soybean oil TG and DSC curves.

For both samples, the oxidation onset between steps 1-2 shows an increase of the mass of the samples that is related to the formation oxygenated compounds (e.g., peroxides). Oxidations are exothermic events, as presented in Figures 5a and $5 \mathrm{~b}$. The mass increase has a maximum, and from this point (between steps 2-3) the oxidation/degradation begins, which causes mass loss with the formation of short-chain

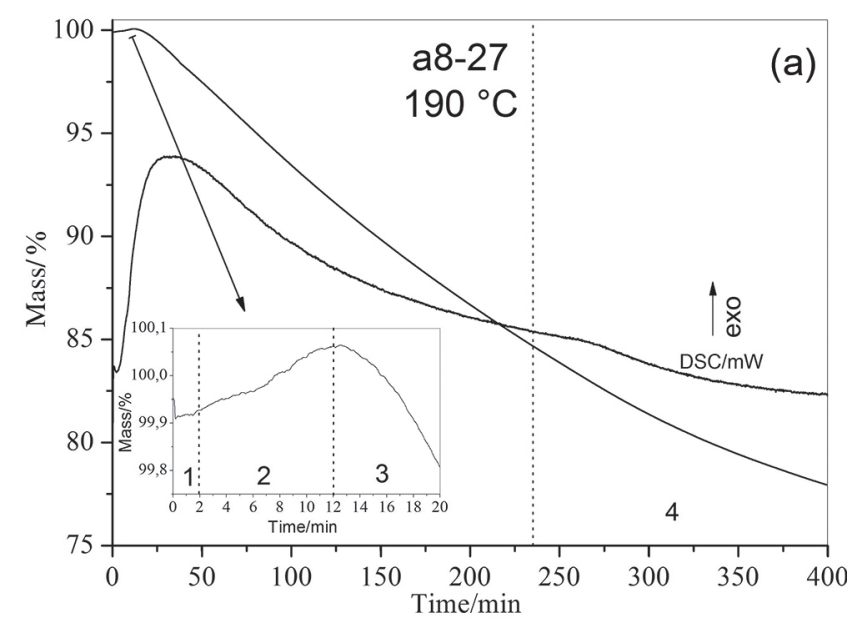

molecules. For the palm olein ( $77.5 \%$ of residual mass) sample, the final oil mass indicates a higher production of volatile compounds than in the soybean oil ( $87.5 \%$ of residual mass). This demonstrates that palm olein is more unstable under these conditions. The mass loss continues until the end of the analysis (400 min). By observing the palm olein and the soybean oil DSC curves, it is possible to notice exothermic events at 240 and $180{ }^{\circ} \mathrm{C}$, respectively, (steps 3-4). It is quite an energetic event for soybean oil and this exothermic peak probably occurs at the beginning of the trans structures oxidation/saturation reaction.

Despite of the complexity of the reactions, the stage 3 of the mass loss, observed in Figure 8 (TG curve of the samples), shows a constant velocity: so, the reaction order can be assigned as pseudo zero and hence follows equation 1 :

$\mathrm{dm} / \mathrm{dt}=-\mathrm{k}(\mathrm{T})$

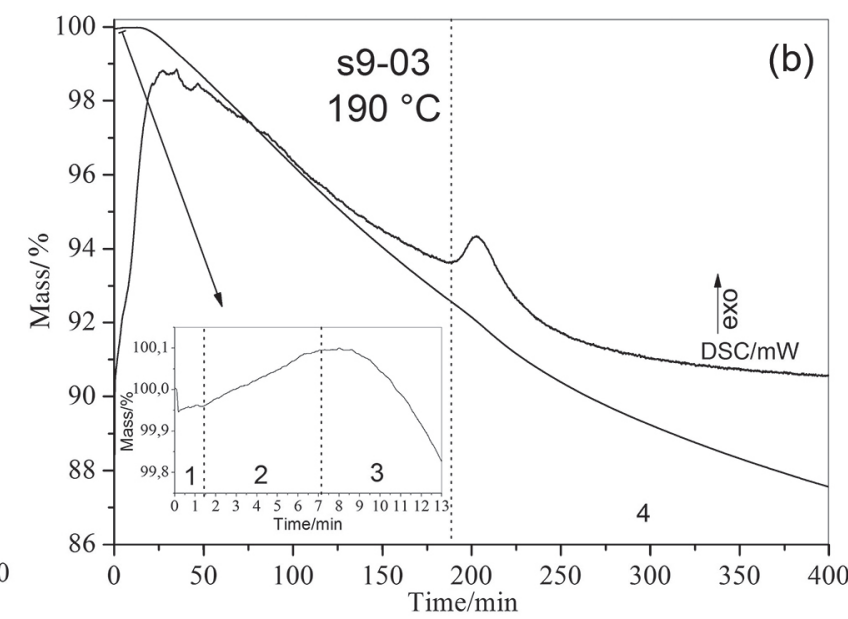

Figure 8. TG and DSC curves of the (a) palm olein and (b) soybean commercial oil samples under an oxidizing atmosphere at $190{ }^{\circ} \mathrm{C}$ for $400 \mathrm{~min}$. 
where $\mathrm{dm} / \mathrm{dt}$ is the mass gradient by time; $\mathrm{k}(\mathrm{T})$ is a temperature-dependent constant. Therefore, it was possible to calculate the activation energy $\left(E_{a}\right)$ and the Arrhenius pre-exponential factor (A) for step 3 of the TG curves of the oils by using the Arrhenius equation (equations 2 and 3). ${ }^{30}$

$\mathrm{k}(\mathrm{T})=\mathrm{Ae}^{-\mathrm{E} a / \mathrm{RT}}$
$\ln \mathrm{k}=\ln \mathrm{A}-(1 / \mathrm{T}) \mathrm{E}_{\mathrm{a}} / \mathrm{R}$

The temperatures used for $\mathrm{E}_{\mathrm{a}}$ and $\mathrm{A}$ determinations were $170,180,190$, and $200^{\circ} \mathrm{C}$. The linear fit for the palm olein and the soybean oil data are presented in Figure 9.

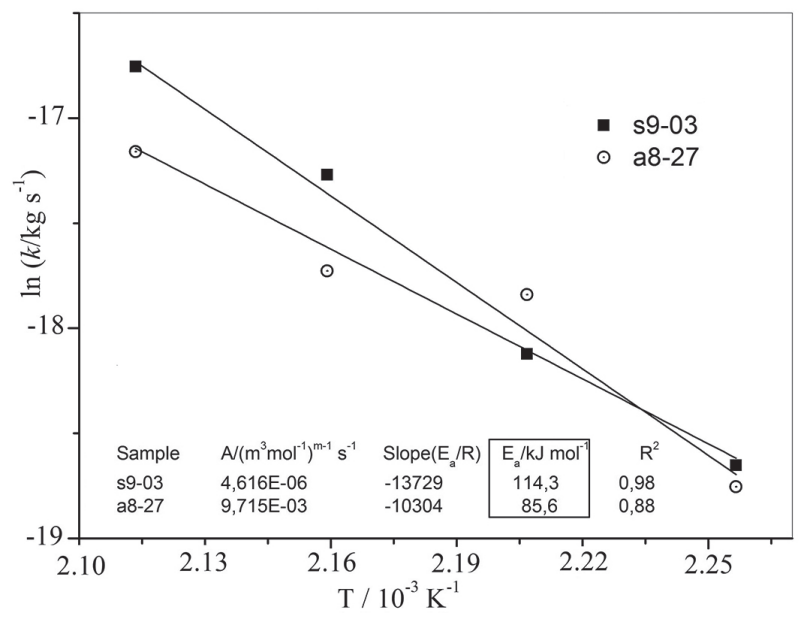

Figure 9. The linear fitting of the Arrhenius equation for step 3 for the soybean oil and the palm olein.

The mass loss at this stage presents a coefficient of determination of the linear regression 0.98 for the soybean oil and 0.88 for the palm olein. Fitting these data was also performed in a first order equation, however the fitted linear coefficient had lower values than for the pseudo zero order: 0.87 , for the soybean oil, and 0.82 , for the palm olein. From these values, it is possible to assume that the soybean oil mass loss is a more constant process regarding the temperature variation, demonstrating that it is thermodynamically more stable than the palm olein. The $\mathrm{E}_{\mathrm{a}}$ values were 114 and $86 \mathrm{~kJ} \mathrm{~mol}^{-1}$, respectively.

\section{Conclusions}

The industrial frying process used on the industrial production of pre-fried breaded chicken causes thermal oxidation and decomposition of oils. As a consequence, the food industry should be particularly concerned about the origin and the quality of the lipid matrix used in their processes. The characterization of the commercial oils performed in this study showed that the palm olein presents a higher content of saturated fatty acids, whereas partially hydrogenated soybean oil contains a higher composition of trans molecules. The occurrence of saturated triglycerides in the palm olein imparts to this oil a certain natural resistance to oxidation and higher thermal degradation onset temperature in an inert and an oxidizing atmosphere. However, the isothermal mass loss degradation step of the partially hydrogenated soybean oil in an oxidizing atmosphere showed a lower reaction rate and higher activation energy than the palm olein. This effect is visible in the IR spectrum of the a 84 sample, since with four days of use in the industry, the hydroxyl signal is apparent; in the soybean oil this signal does not appear even with four days of use. Determination of the kinetic reaction parameters becomes quite important in the food industry, as the oils used industrially in the food pre-frying process remain at $190-20{ }^{\circ} \mathrm{C}$ for several hours under an oxidizing atmosphere. After the thermal oxidation starts, the degradation rate of the oils must be monitored in order to avoid the formation of short-chain molecules, which may be toxic to mammals, and induces the mechanisms retarding the oxidation onset and, hence, the oxidative degradation steps.

\section{Acknowledgments}

The authors would like to thank the CNPq (Conselho Nacional de Desenvolvimento Científico e Tecnológico), Fundação Araucária, and CAPES (Coordenação de Aperfeiçoamento de Pessoal de Nível Superior) for granting doctoral and postdoctoral scholarships.

\section{Author Contributions}

Alex Sanches Torquato was responsible for conceptualization, data curation, formal analysis, writing original draft, writing-review and editing, investigation; Paulo Rodrigo Stival Bittencourt for formal analysis, writing-review and editing, investigation; Fernando Reinoldo Scremin for formal analysis, investigation; Rosana Aparecida da Silva-Buzanello for formal analysis, investigation; Thays Raphaela Gonçalves for formal analysis, writing-review and editing; Makoto Matsushita for project administration, resources, writing-review and editing.

\section{References}

1. Sun, Y.; Zhang, M.; Fan, D.; Ultrason. Sonochem. 2019, 51, 77.

2. Sanz, T.; Salvador, A.; Fiszman, S. M.; Food Hydrocolloids 2004, 18, 227.

3. Kurek, M.; Ščetar, M.; Galić, K.; Food Hydrocolloids 2017, 71, 225 . 
4. Bansal, G.; Zhou, W.; Barlow, P. J.; Joshi, P.; Leng, F.; Ling, H.; Food Chem. 2010, 121, 621.

5. Lim, J.; Jeong, S.; Oh, I. K.; Lee, S.; LWT--Food Sci. Technol. 2017, 84, 788.

6. Waghmare, A.; Patil, S.; LeBlanc, J. G.; Sonawane, S.; Arya, S. S.; Algal Res. 2018, 31, 99.

7. Quan, X.; Zhang, M.; Fang, Z.; Liu, H.; Food Bioprod. Process. 2016, 99, 109.

8. Armylisas, A. H. N.; Hazirah, M. F. S.; Yeong, S. K.; Hazimah, A. H.; Grasas Aceites 2017, 68, e174.

9. Ustra, M. K.; Silva, J. R. F.; Ansolin, M.; Balen, M.; Cantelli, K.; Alkimim, I. P.; Mazutti, M. A.; Voll, F. A. P.; Cabral, V. F.; Cardozo-Filho, L.; Corazza, M. L.; Oliveira, J. V.; J. Chem. Thermodyn. 2013, 58, 460.

10. Sanmartin, C.; Venturi, F.; Sgherri, C.; Nari, A.; Macaluso, M.; Flamini, G.; Quartacci, M. F.; Taglieri, I.; Andrich, G.; Zinnai, A.; Heliyon 2018, 4, e00888.

11. Kurtulbaş, E.; Bilgin, M.; Şahin, S.; Ind. Crops Prod. 2018, 124, 593.

12. Zhao, H.; Feng, J.; Zhu, J.; Yu, H.; Liu, Y.; Shi, P.; Wang, S.; Liu, S.; J. Cleaner Prod. 2020, 242, 118274.

13. Silva, J. C. M.; Nicolau, C. L.; Cabrala, M. R. P.; Costa, E. R.; Stropa, J. M.; Silva, C. A. A.; Scharf, D. R.; Simionatto, E. L.; Fioruccic, A. R.; Oliveira, L. C. S.; Simionatto, E.; Fuel 2020, 242, 116644.

14. Jiang, S.; Xie, Y.; Li, M.; Guo, Y.; Cheng, Y.; Qian, H.; Yao, Y.; Food Chem. 2020, 309, 125714.

15. Shi, M.; Ying, D.; Hlaing, M. M.; Ye, J.; Sanguansri, L.; Augustin, M. A.; Food Res. Int. 2020, 132, 109050.

16. Bittencourt, P. R. S.; Scremin, F. R.; J. Polym. Environ. 2019, 27, 612 .
17. Morais, D. R.; Rotta, E. M.; Sargi, S. C.; Bonafe, E. G.; Suzuki, R. M.; Souza, N. E.; Matsushita, M.; Visentainer, J. V.; J. Braz. Chem. Soc. 2017, 28, 308.

18. Martín-Lara, M. A.; Ronda, A.; Blázquez, G.; Pérez, A.; Calero, M.; Process Saf. Environ. Prot. 2018, 113, 448.

19. Ma, X.; Liu, F.; Zhou, S.; Helian, Y.; Wu, Z.; Li, H.; Zhang, L.; Li, Y.; Energy Convers. Manage. 2018, 180, 401.

20. Santos, J. C. O.; Santos, I. M. G.; Conceição, M. M.; Porto, S. L.; Trindade, M. F. S.; Souza, A. G.; Prasad, S.; Fernandes, V. J.; Araújo, A. S.; J. Therm. Anal. Calorim. 2004, 75, 419.

21. da Silva, C. M.; Zanqui, A. B.; Gohara, A. K.; de Souza, A. H. P.; Cardozo-Filho, L.; Visentainer, J. V.; Chiavelli, L. U. R.; Bittencourt, P. R. S.; da Silva, E. A.; Matsushita, M.; J. Supercrit. Fluids 2015, 102, 1.

22. Berdeaux, O.; Fontagné, S.; Sémon, E.; Velasco, J.; Sébédio, J. L.; Dobarganes, C.; Chem. Phys. Lipids 2012, 165, 338.

23. Sarangapani, C.; Ryan Keogh, D.; Dunne, J.; Bourke, P.; Cullen, P. J.; Food Chem. 2017, 235, 324.

24. Guillén, M. D.; Uriarte, P. S.; Food Chem. 2012, 131, 915.

25. Choe, E.; Min, D. B.; J. Food Sci. 2007, 72, R77.

26. Silva, V. L. O.; Melo, J. A.; Oliveira, L. B.; Pedroso, L. R.; Simionatto, E. L.; de Matos, D. I.; Scharf, D. R.; Figueiredo, E. S.; Wisniewski Jr., A.; Renewable Energy 2019, 135, 945.

27. Kmiecik, D.; Kobus-Cisowska, J.; Kulczyński, B.; J. Am. Oil Chem. Soc. 2018, 95, 473.

28. Öztürk, C.; Küsefoglu, S. H.; J. Appl. Polym. Sci. 2010, 118, 3311.

29. Mossoba, M. M.; Milosevic, V.; Milosevic, M.; Kramer, J. K. G.; Azizian, H.; Anal. Bioanal. Chem. 2007, 389, 87.

30. Hotová, G.; Slovák, V.; Thermochim. Acta 2018, 666, 82.

Submitted: March 20, 2020

Published online: May 15, 2020 